\title{
Finite element analysis of a thermally insulated infrared radiant emitter
}

\author{
Anton N. Ermolaev ${ }^{1, *}$, Olga V. Khaustova ${ }^{2}$, and Anastasia P. Yakovets ${ }^{2}$ \\ ${ }^{1}$ Tyumen industrial University, 625000 Tyumen, Russia \\ ${ }^{2}$ National Research Tomsk Polytechnic University, 634050 Tomsk, Russia
}

\begin{abstract}
The purpose of this work is to analyze the efficiency of the technical solution that is based on thermal insulation of the infrared radiant burner outer surface and to identify of the characteristics of combustion and heat and mass exchange processes. Calculation of the heat balance is performed for thermal capacities of $5,10,15,20,30,40 \mathrm{~kW}$ and proceeding from the main goal that was to generate directed local heating of workplaces and production areas. We used Ansys Multiphysics software and Fluent CFD solver to implement finite element analysis. Calculation of the thermal insulation layer thickness for a given external surface temperature was additionally performed. The technical solutions offered provides an optimal thermal regime in the whole building and enable us to increase the efficiency of the high temperature infrared radiant emitter to 2$17 \%$ and a consequence of the system as a whole.
\end{abstract}

\section{Formulation of the aim}

Radiant heating systems based on gas-fired infrared heat emitters are used to effectively heat large-scale premises [1-5]. Temperature of emitter's ceramic surfaces can exceed 1000 ${ }^{\circ} \mathrm{C}[3,4,6]$. This issue creates a list of problems that require a number of technical solutions to solve them [3-5, 7-10].

The purpose of this work is to analyze the efficiency of the technical solution that is based on thermal insulation of the infrared radiant burner outer surface (Fig. 1) and to identify of the characteristics of combustion and heat and mass exchange processes. Series of numerical and experimental studies was carried out using licensed software and a certified attorney base to solve the tasks [1]. The results of the development of a finite element parametric model of a gas infrared heating system containing a radiation source and irradiation surfaces are presented. Standard model of infrared radiant gas burner and its modification with a low thermal conductivity coefficient of the reflector were examined (Fig. 1, b).

Calculation of the heat balance is performed for thermal capacities of $5,10,15,20,30$, $40 \mathrm{~kW}$ and proceeding from the main goal that was to generate directed local heating of workplaces and production areas. Calculation of the thermal insulation layer thickness for a

\footnotetext{
Corresponding author: ermolaevanton03@gmail.com
} 
given external surface temperature was additionally performed. The thermal insulation thickness is equal to $50 \mathrm{~mm}$ according to the calculation results.

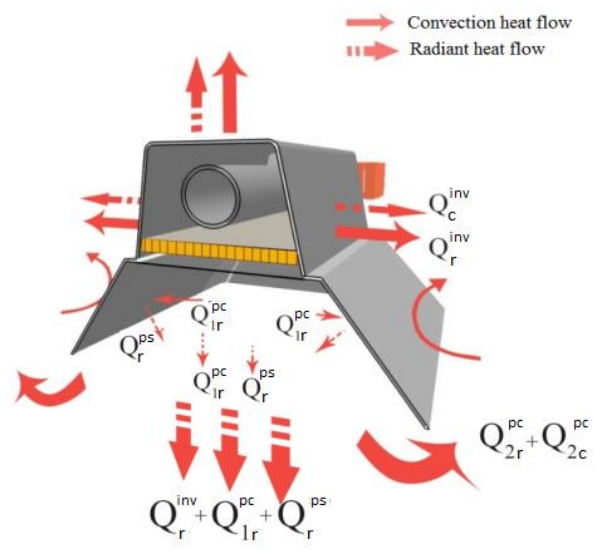

(a)

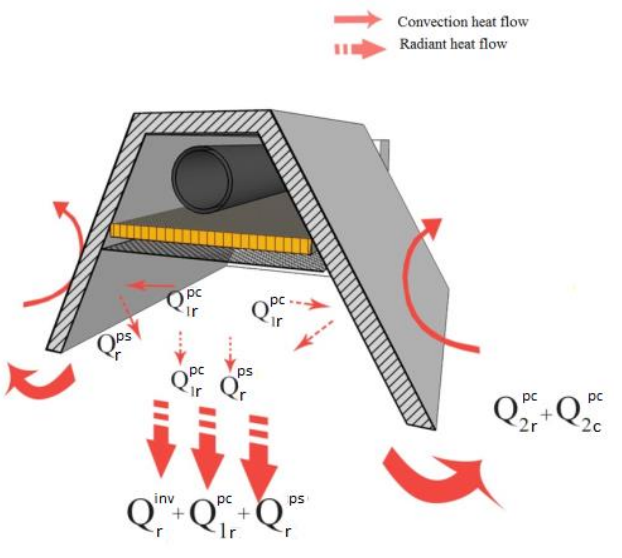

(b)

Fig.1. Diagram of the movement of heat flows during the operation of the standard (a) and isolated (b) model of high-temperature radiator.

\section{Method of the research}

We used Ansys Multiphysics software and Fluent CFD solver to implement finite element analysis. A number of heat transfer problems [3-6, 11-15] in ventilated rooms with radiation sources of heating have been solved by simulating the diffusion combustion processes in infrared radiant gas burner and turbulent gas flow using the Discrete Ordinates DO model for calculating radiant heat transfer:

$$
\frac{d I(\vec{r}, \vec{s})}{d s}+\left(a+\sigma_{s}\right) I(\vec{r}, \vec{s})=a n^{2} \frac{\sigma T^{4}}{\pi}+\frac{\sigma_{s}}{4 \pi} \int_{0}^{4 \pi} I\left(\vec{r}, \vec{s}^{\prime}\right) \Phi\left(\vec{s}, \vec{s}^{\prime}\right) d \Omega^{\prime}
$$

where T - temperature; $\sigma$ - The Stefan's constant; $I$ - intensity of radiation; $\Phi$ - phase function; $\Omega$ - solid angle; $r$ - position vector; $s$ - direction vector of radiation; $s$ ' - direction vector of scattering; $a$ - coefficient of absorption; $n$ - refractive index; $\sigma_{s}$ - coefficient of scattering.

To solve the differential equations of heat and mass exchange it was considered that the gas-fired infrared heat emitter is made of steel $12 \mathrm{Cr} 18 \mathrm{Ni} 10 \mathrm{Ti}$ of $2 \mathrm{~mm}$, the gas pressure before the inlet nozzle was $1270 \mathrm{~Pa}$, the air-fuel ratio (AFR) is 9.996 , fuel is $100 \%$ methane and oxidizer is $21 \%$ oxygen and $79 \%$ nitrogen. Gas-fired infrared heat emitters with heat output of $5,10,15,20,30,40 \mathrm{~kW}$ were investigated. 


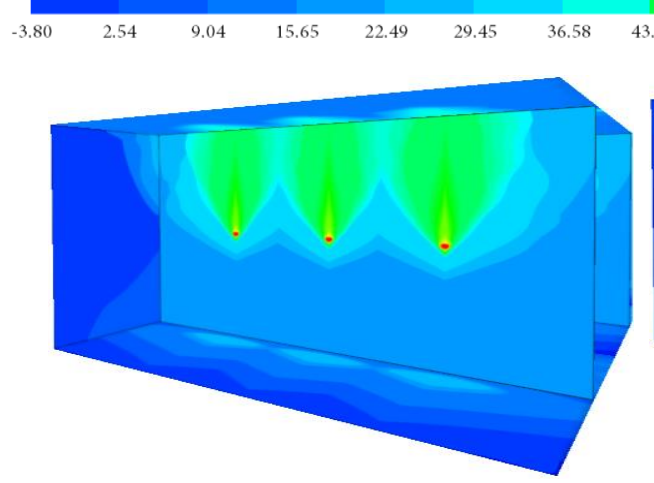

(a)

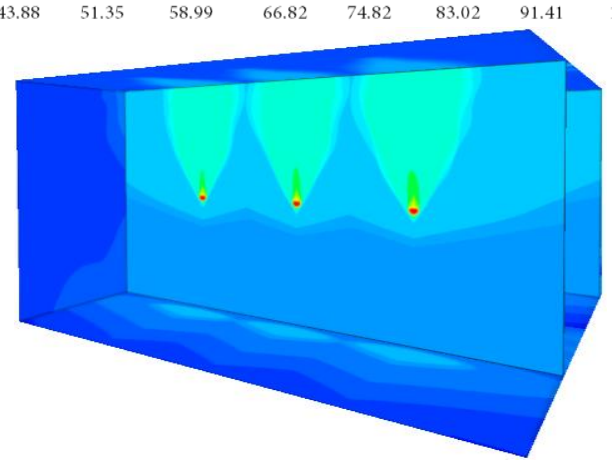

(b)

Fig. 2. Temperature fields in the volume and on the surfaces of the production room $\left({ }^{\circ} \mathrm{C}\right)$ when the emitters of typical (a) and insulated (b) model with a capacity of $10 \mathrm{~kW}$ are placed at a height of $6 \mathrm{~m}$.

\section{Results and Conclusion}

Analysis of the obtained data indicates that efficiency of radiator is increased with increasing of its thermal power. This is due to the fact that the heat exchange area (the area of the burner construction) increases with increasing of thermal power disproportionally. As a result, the heat losses of the burner outer surface are reduced to a unit of power. In turn, heat losses with outgoing gases increase because the number of ceramic plates increases with increasing of heat power with an average unit of power of $1.5 \mathrm{~kW}$. It leads to increasing of the combustion products volume and to their less intensive dilution in the air masses.

The use of insulation has made it possible to achieve the following efficiency indicators:

- the volume of heat transferred in the direction of the working area was 3089-24715 W or $63 \%$ of the available heat;

- the heat losses with outgoing gases were $1841-14730 \mathrm{~W}$ or $37 \%$;

- efficiency increase of $2-5 \%$ depends on the thermal output.

The increase of heat losses with outgoing gases in the insulated model is explained by a decrease of the heat transfer intensity from the reflector internal surface to the outer one. As a result, there is a decrease of the convective heat transfer from the combustion products of the region bounded by the reflector to the wall of the reflector inner surface.

The technical solutions offered provides an optimal thermal regime in the whole building and enable us to increase the efficiency of the high temperature infrared radiant emitter to $2-17 \%$ and a consequence of the system as a whole. In addition, a part of heat losses by the burner with outgoing gases will decrease, that will solve the problem of overheating of the upper room zone.

\section{References}

1. Y. M. Luo, L. Chevalier, F. Utheza, X. Nicolas, Int. Polym. Process. 30, 554 (2015)

2. M. Ostafin, M. Balkenhol, J. Erlemeyer, M. Köhler. Mater. Werks. 41, 11 (2010)

3. A. N. Ermolaev, O. V. Khaustova, MATEC Web Conf. 141, 01019 (2017)

4. A. N. Ermolaev, S. A. Khaustov, MATEC Web Conf. 110, 01024 (2017) 
5. A. N. Ermolaev, S. A. Khaustov, MATEC Web Conf. 110, 01038 (2017)

6. S. Dolgov, E. Savchenko, S. Khaustov, R. Tabakaev, A. Zavorin, EPJ Web Conf. 110, 01074 (2016)

7. S. A., Khaustov Belousova Y. A., Buvakov K. V., Dolgih A. Y., Kulesh R. N. IFOST 2016 Proceedings 2, 548 (2016)

8. J. A. Oraz, I. E. Korzilova, A. N. Ermolaev, S. A. Khaustov, A. Y. Dolgih, MATEC Web Conf. 92, 01001 (2016)

9. K. A. Al-attab, J. C. Ho, Z. A. Zainal, Exp. Therm Fluid Sci. 62, (2015).

10. D. Patino, B. Crespo, J. Porteiro, J. L. Miguez, Appl Therm Eng. 100, 849 (2016)

11. P. S. Gergelizhiu, S. A. Khaustov, R. B. Tabakaev, P. Y. Novoseltsev, A. V. Kazakov, A. S. Zavorin, Proc. of 2014 Int. Conf. on Mechanical Engineering, Automation and Control Systems (Tomsk, 2014)

12. S. A. Khaustov, A. S. Zavorin, K. V. Buvakov, N. A. Zakharushkin, MATEC Web Conf. 19, 01020 (2014)

13. S. A. Khaustov, A. S. Zavorin, K. V. Buvakov, L. D. Kudryashova, A. V. Tshelkunova, EPJ Web Conf. 82, 01041 (2015)

14. S. A. Khaustov, A. S. Zavorin, K. V. Buvakov, V. A. Sheikin, EPJ Web Conf. 82, 01039 (2015)

15. S. A. Khaustov, A. V. Kazakov, G. A. Cherkashina, L. A. Sobinova, EPJ Web Conf. 110, 01028 (2016) 